\title{
Treating gum disease could help manage type 2 diabetes
}

A new study ${ }^{1}$ has suggested that intensively treating gum disease can help some people with type 2 diabetes by lowering their blood glucose level and reduce their risk of diabetes-related complications.

Gum disease affects almost half of the UK population and people with diabetes have a higher risk of developing it.

Researchers from University College London's Eastman Dental Institute carried out a trial - funded by Diabetes UK and the NIHR Biomedical Research Centre - involving 264 patients with poorlycontrolled diabetes and moderate to severe periodontitis.

Between 1 October 2008 and 31 October 2012, half of the participants received intensive treatment for their gum disease, which involved deep cleaning their gums and minor gum surgery. The other half received standard care, involving regular cleaning and polishing of their teeth. The treatments were provided alongside any Type 2 diabetes medications being taken.

After 12 months, those who has received the more intensive gum therapy had reduced their blood glucose level by, on average, $0.6 \%$ more than the standard care group. They also showed reduced chronic inflammation, which could lower their risk of serious diabetes-related complications, such as heart disease, stroke and kidney disease.

The findings, published in The Lancet Diabetes and Endocrinology on 24 October 2018, are thought to be the first to link intensive gum disease treatment to improvements in kidney and blood vessel function and chronic inflammation.

Lead researcher and Professor of Periodontology Francesco D’Aiuto said: 'Gum disease is closely linked to diabetes and it is well known that it can lead to a higher blood glucose level as well as chronic inflammation around the body, which both could promote the development of kidney and vessel damage if sustained for long periods of time.

'This is the first long-term, randomised study to show a substantial benefit of treating gum disease on diabetes control.

'Lowering blood glucose level by $0.6 \%$ is the equivalent of prescribing a patient an additional, second blood sugar lowering drug. We were delighted with the improvement in health and quality of life of those in the test group compared with those in the control group whose teeth were only given a scale and polish.'

The researchers are closely working with NHS authorities to increase awareness of the link between gum disease and diabetes amongst diabetes professionals, suggesting the inclusion of dental and gum assessments for people with diabetes as standard practice.

England's Chief Dental Officer Sara Hurley said: 'This new research helpfully builds on what we already know about the importance of patients with diabetes receiving vital gum assessments and it allows us to work closer with the wider NHS to improve the overall health and quality of everyday life for these patients.'

The team now plan a larger study at national level to test the possible benefit of treating gum disease in patients who are at risk of heart-attacks or strokes.

Dr Elizabeth Robertson, Director of Research at Diabetes UK, said: 'Currently people with type 2 diabetes aren't given oral health advice or treatment as part of their routine diabetes care.

'While more work is needed to fully understand how good oral health could help with blood glucose management, this research gives us important insights into the potential benefits of looking after your oral health if you have type 2 diabetes.'

Alongside this research, Diabetes UK has been working closely with the Office of the Chief Dental Officer for England and others to develop a commissioning standard for dental care for people with or at risk of type 2 diabetes. Once developed, this standard will support the development of clinical care pathways that aim to improve both general and oral health outcomes, by ensuring that patients with diabetes who go to see their GP are also referred to their dentist.

1. D'Aiuto F, Gkranias, N, Bhowruth D et al. Systemic effects of periodontitis treatment in patients with type 2 diabetes: a 12 month, single-centre, investigator-masked, randomised trial (24 October 2018). The Lancet Diabetes \& Endocrinology 2018; DOI:10.1016/ S2213-8587(18)30038-X. Available at https://www.thelancet.com/journals/landia/article/ PIIS2213-8587(18)30038-X/fulltext (accessed on 4 November 2018).

\section{Library retirement}

Roger Farbey, Head of Library and Knowledge Services at the BDA library for 27 years, has retired.

During his tenure, he digitised the library catalogue, began the very first BDA website, saw the Medline service move from CD-ROM to online, and witnessed the birth of e-books.

On 26 July 2018, staff old and new bade him farewell. During his speech, Roger made reference to the continual changing nature of technology, alluding to the old telephone dial-up Medline system, floppy disks and video cassettes - all now redundant - which were in use when he started at the BDA.

During the party, being a keen fan of the TV show 'The Prisoner', he was presented with a crystal glass clock engraved with the message: 'I have retired! I will not be pushed, filed, indexed, catalogued, or numbered! My time is my own!'.

In addition, he was given a print of a watercolour of the BDA's Headquarters and $£ 100$ of Amazon vouchers.

Roger's successor, Helen Nield has herself been at the BDA as



Library Manager for more than 20 years. She is keen to continue the mixture of stability, innovation and superb customer service that makes the BDA library arguably the best dental library in the world. Watch out for a new service later in the year.

By Helen Nield 